\title{
Assessment of Depression among Musculoskeletal Fracture Patients in a Tertiary Referral Hospital in Bangladesh
}

\author{
Koushik Roy ${ }^{1}$, Selim Hossain ${ }^{1}$, Md. Abdul Awal Lilon', Nasima Yasmin ${ }^{1}$, Susmita Sarkar ${ }^{1}$, Krishna Roy ${ }^{2}$, \\ Abdul Haque ${ }^{3}$, Mahbub Jobayer ${ }^{4}$, Banossree Saha ${ }^{4}$, and Ropak Chandra Roy ${ }^{1}$ * \\ ${ }^{1}$ Department of Physiotherapy, Gono Bishwabidyalay, Savar, Dhaka, Bangladesh; ${ }^{2}$ Department of Psychiatry, Bangabandhu \\ Sheikh Mujib Medical University, Dhaka, Bangladesh; ${ }^{3}$ Cumilla Medical College Hospital, Cumilla, Bangladesh; ${ }^{4}$ Gono- \\ shasthya Samaj Vittik Medical College Hospital, Savar, Dhaka, Bangladesh. \\ *Correspondence: ropak.mph111@gmail.com (Ropak Chandra Roy, Lecturer, Dept. of Physiotherapy, Gono Bishwabidyalay, \\ Savar, Dhaka, Bangladesh).
}

\begin{abstract}
Psychological therapy is very important in musculoskeletal fracture patients for mental support. The study was conducted National Institute of Traumatology and Orthopedic Rehabilitation (NITOR), Dhaka. 102 participate in this study. Patients with a musculoskeletal disorder are commonly treated by physical therapists; it influences clinically relevant outcomes such as pain and disability but not influence a treated psychological disorder. Psychological therapy is very important relatively to treat of physical therapy. It found that the severe of injury moderate $20 \%$, serious $2.4 \%$, severe $77.1 \%$ depression on musculoskeletal fracture, he/she feel sad $41.0 \%$, sad all the time $44.0 \%$, so sad $14.5 \%$,Indicates minimal depression $1.2 \%$, mild depression $12 \%$, moderate depresssion $81.9 \%$, severe depression $4.8 \%$. It is found that the mean depressed mood of the respondent's sadness $94.0 \%$, frequent weeping $6.0 \%$, in agitation occasional $7.2 \%$, frequent $92.8 \%$, anxiety no difficulty $1.2 \%$, tension irritability $89.2 \%$, fear $9.6 \%$ depression on musculoskeletal fracture. So that the Musculoskeletal fracture in our country is more vulnerable and mental health is not so good.
\end{abstract}

Keywords: Assessment, Depression, Musculoskeletal fracture, Tertiary referral hospital, and Bangladesh.

\section{INTRODUCTION:}

Psychology can be defined as a science of behaviour and mind, including conscious and unconscious phenomena, as well as thought. Academically psychology discipline has immense scope and diverse interests that, when taken together, seek an under-standing of the emergent properties of brains, and all the variety of epiphenomena they manifest (Fernald, 2008). It aims to understand individuals and groups by establishing general principles and researching specific cases as a social science. In this psychology field, a professional UniversePG I www.universepg.com practitioner or researcher is called a psychologist and can be classified as a social, behavioural, or cognitive scientist (Parker et al., 2002). Psychologists tries to understand the role of mental functions in individual as well as social behaviour, while also wants to explore the physiological and biological processes that underlie cognitive functions and behaviours (Wikipedia, 2018).

Fracture of a bone is a medical condition in which there is a breach in the continuity of the bone. Fracture of a bone may be the result of high force impact or stress, or with a minimal trauma injury due to certain 
medical conditions that weaken the bones, such as osteoporosis, osteopenia, bone cancer, or ontogenesis imperfect, where the fracture is then properly termed a pathologic fracture (Katherine, 2013). There is a defined association between physical injury and disability and emotional distress. There is an increasing awareness that patient outcomes following orthopaedic trauma surgery do not depend solely on the success of the operative procedure. Emotional distress has been shown to affect physical function, overall outcomes, and post injury productivity levels (Patricia et al., 2016). There is a known connection between physical injury and disability and emotional distress. There are several research works has shown a relationship between trauma, depression, and poor outcomes. Though literature on relation between trauma and depression is limited in regarding clarifying the relationship between the degree of injury and depression and the relationship between physical function of patients with less severe injuries and depression (Demyttenaere and De Fruyt, 2003; Nahid et al., 2019).

Although trauma remains the leading cause of mortality in the first 4 decades of life, most people with traumatic injuries will survive their accident. As trauma care has improved substantially during recent decades and has led to higher survival rates and there has also been an increasing focus on thepatients' perceived health-related quality of life (HRQOL) as an outcome after trauma (Amit Chaitanya, 2015). Quality of life is an important issue for the large number of patients who may need to adapt to severe and chronic disability due to joint stiffness. The loss of mobility in the joints makes patient more dependent on others which affects their quality of life. Any loss of ability to live independently in the community has a considerable detrimental effect on their quality of life. It follows that reduction in the incidence of fractures will not only save lives but will prevent a significant reduction in their quality of life (Amit Chaitanya, 2015).

Trauma remains the prime cause of mortality in the first 4 decades of life, most people with traumatic injuries will survive their accident Psychiatric complications of physical injury are a public health concern. Following orthopaedic trauma, recovery depends on UniversePG I www.universepg.com the outcome of mental health. Poor mental health, development of symptoms of PTSD (Post Traumatic Stress Disorder), depression and increased substance abuse leads to poor recovery. Present review article has discussed quality of life on patients following orthopaedic trauma with emphasis on the psychological distress (Amit Chaitanya, 2015).

The pathological environment of prolonged abuse fosters responsible for the development of psychiatric symptoms. History of abuse, especially childhood abuse, appears to be one of the major contributing factors predisposing a person to become a psychiatric patient. Though only a minority of survivors of chronic childhood abuse ultimately become psychiatric patients, a large proportion of adult psychiatric patients are survivors of childhood abuse (Briere and Runtz, 1987). Repetitive trauma appears to amplify and generalize the physiologic symptoms of PTSD. Chronically traumatized people are hyper vigilant, anxious and agitated, without any recognizable baseline state of calm or comfort (Hilberman, 1980). Psychologists have studied individual characteristics in an attempt to find explanations as to why similar work and organisational characteristics are associated with varying degrees of well-being amongst people (Roy et al., 2019; Frank and Emma, 2010).

\subsection{Justification of the Study}

Patients with musculoskeletal disorder are commonly treated by physical therapists, it influence clinically relevant outcomes such as pain and disability but not influence to treated psychological disorder. Psychological therapy is very important relatively to treat of physical therapy. Considerable detrimental effect on quality of life if any loss of ability to live independently in the community. It indicates that reduction in the cases of fractures will not only save lives but will also prevent a significant reduction in their quality of life. Having a good knowledge in health related quality of life predictors after injury may enable us to optimize and individually tailor interventions at an early stage in treatment and rehabilitation process.

\subsection{Statement of Hypothesis}

1.3.1 Null Hypothesis - There is no significant effectiveness of musculoskeletal fracture and depression. 
1.3.2 Alternate Hypothesis - There is significant effectiveness of musculoskeletal fracture and depression.

\section{Review of Literature}

The prevalence of clinically relevant depression approached $45 \%$ in a diverse cohort of orthopaedic trauma patients. Global disability is strongly correlated with depression. A case of an open fracture may also increase the risk of depression in many folds (Butcher et al., 1996). Psychological acceptance (also referred to as acceptance) may be described as willingness to experience thoughts, feelings, and physiological sensations, especially those which are negatively evaluated (e.g. fear), without trying to avoid them, or let them consider as one's actions. Emotional intelligence (EI) describes people's ability to perceive, Understand, assimilate and regulate their emotions (Wikipedia, 2018). A good deal of importance has been given to the potential predisposition of negative affectivity and anxiety sensitivity in fear related to pain symptoms. Acceptance involves a willingness to experience all psychological events (i.e. thoughts, feelings, and sensations), without changing, avoiding, or otherwise controlling them (IASP, 2017).

(Demyttenaere and De Fruyt, 2003) Consistent with this conceptualisation of psychological acceptance, there is a great deal of research that implicates this individual characteristic in a wide range of psychological problems, from substance abuse to depression and suicide. Refers to 'the ability to perceive and express emotion, assimilate emotion in thought, understand and reason with emotion, and regulate emotion in self and others'. The term 'emotional intelligence' has received a great deal of attention in the applied psychology and popular press (Wikipedia, 2018). (Lasa et al., 2000) Edition to the problems of over reporting and underreporting, accurate prevalence estimates of physical and sexual abuse of women in the general population are somewhat difficult to obtain because of a lack of comprehensive studies and of uniform definitions of physical and sexual assault or abuse.

Although some women with schizophrenia may benefit from a more gradual form of traditional exposurebased treatment, as with other groups of trauma UniversePG I www.universepg.com survivors (Glancy et al., 1992). Unlike the onedimensional biomedical perspective, which focuses on etiological and pathophysiological explanations for chronic pain, or the psychogenic view, which suggests pain as physical manifestations of psychological difficulties, a bio psychosocial view provides an integrated model that incorporates purely mechanical and physiological processes as well as psychological and social-contextual variables that may cause and perpetuate chronic pain.

People who attribute their symptoms to an injury appear more likely to view any physical sensation as harmful and noxious, thereby increasing anxiety. These changes may, consequently, lower pain thresholds and tolerance, further increase activity avoidance and functional limitations, and facilitate general deconditioning. Even when there is no difference in physical pathology between those who attribute symptom onset to a traumatic event and those who perceive their symptoms has having an insidious onset (Rannaparekh, 2017).

Patients who describe their pain as a consequence of accidental injury are significantly more likely to be prescribed physical and pharmacological modalities for symptomatic relief, including nerve blocks, physical therapy, transcutaneous electrical nerve stimulation, and opioid medication.

Chronic pain patients with elevated pain-related anxiety tend to anticipate higher levels of pain than those with low anxiety, and anticipation of pain often results in poorer behavioural performance. Physical activities and work tasks is more strongly associated with disability and work loss during the previous year than are biomedical variables and characteristics of pain. They concluded that "fear of pain and what we do about it is more disabling than the pain itself".

Counter conditioning by means of graded exposure to a feared stimulus is an effective treatment for people suffering from excessive fear (Patten et al., 2001). Negative affectivity, the general tendency to experience subjective distress and dissatisfaction, has been demonstrated to be associated with elevated symptom reporting by chronic pain patients (McCarthy et al., 2003). Despite these general conclusions about psychosocial predictors of disability, the results must 
be interpreted cautiously, as there are methodological problems inherent in each study that make generalizations based on the body of research problematic (Wikipedia, 2018).

Psychological treatments for chronic pain are most effective when incorporated with other treatment components or modalities. Examined the effectiveness of an outpatient program for FMS that included family education along with physical and psychological components. Patients demonstrated significant improvements on measures of pain, interference of symptoms. Patients whose painful symptoms follow an accident have been shown to be more refractory to treatment than patients with non-traumatic onset. Psychological factors have been reported to be predictive of long-term disability for many pain syndromes as well as for pain severity, emotional distress, and treatment seeking (Wikipedia, 2018). Majority of individuals with spinal cord injuries (SCI) experience chronic pain and this pain can have a substantial negative impact on quality of life. A particularly notable absence in the SCI literature has been research on patient catastrophizing, the phenomenon of expecting or worrying about major negative consequences from a situation, even one of minor importance.

\section{METHODOLOGY:}

\subsection{List of the Key Variable}

Age, sex, Occupation, Marital status, Education, depression, income and Expenditure.

3.1.1 Dependent Variable - Musculoskeletal fracture patient.

3.1.2 In-dependent Variable - Psychological depresssion.

\subsection{Objectives of the Study}

\subsubsection{General Objective}

To assess the level of depression among the musculoskeletal fracture patients in a tertiary referral hospital in Bangladesh?

\subsubsection{Specific Objectives}

1. To assess the social demographic characteristic of the musculoskeletal fracture UniversePG I www.universepg.com patient in a tertiary referral hospital in Bangladesh.

2. To determine the depression level of patient.

3. To find out the history of musculoskeletal complication.

4. To assess the social support in a tertiary referral hospital in Bangladesh.

5. To assess the management of musculoskeletal fracture patient.

3.3 Study design - Mixed Method study.

3.4 Outcome measure - Musculoskeletal and disability index.

3.5 Parameter - Abbreviated Injury Scale (AIS), Beck Depression Scale (BDS), Hamilton Depression Rating Scale (HDRS) (Hamilton, 1960).

3.6 Sample population - The sample population was consisted of male and female who complain of musculoskeletal fracture and depression and consult to the physician in selected hospitals in locations.

3.7 Study area - The study was conducted National Institute of Traumatology and Orthopedic Rehabilitation.

3.8 Study site - National Institute of Traumatology and Orthopedic Rehabilitation (NITOR), Sher-eBangla Nagor, Dhaka. Number of beds -1000 .

Type of hospital - Orthopedic and Rehabilitation hospital, it is a tertiary level government hospital.

Facilities - Indoor and outdoor facilities.

3.9 Study period - This study conducted from $1^{\text {st }}$ January to $2^{\text {th }}$ April 2018.

3.10 Sample size - Following formula was used to determine the sample size.

$n=\frac{z^{2} p q}{d^{2}}$

Here,

$\mathrm{n}=$ the desired sample size

$\mathrm{z}=$ the standard normal deviate usually set at 1.96

which correspondents to $95 \%$ confidence level

$\mathrm{p}=45 \%$ (Patricia et al., 2006)

$\mathrm{q}=1-\mathrm{p}=1.00-0.45$

$\mathrm{q}=0.55$

$\mathrm{d}=$ degree of accuracy desired, usually set at $0.05 \%$. 
Now, required sample size

$$
\begin{gathered}
n=\frac{z^{2} p q}{d^{2}} \\
\mathrm{~N}=\frac{(1.96 \times 1.96) \times .45 \times .55}{(.05 \times .05)}
\end{gathered}
$$

$\mathrm{n}=380.316$

So, required sample size is 380.316

Researcher took 102 samples for time and fund limitation.

\subsection{Statistical tool}

Paired ' $t$ ' test - Paired ' $t$ ' test was conducted to compare the pre-test and post-test values of visual analogue scale for pain and functional disability.

\section{Formula of paired ' $t$ ' test}

$$
\begin{gathered}
S=\sqrt{\frac{\sum d^{2}-\frac{\left(\sum d\right)^{2}}{n}}{n-1}} \\
t=\frac{\bar{d} \sqrt{n}}{s}
\end{gathered}
$$

$d=$ Difference between the pretests versus posttest.

$\bar{d}=$ Mean difference.

$n=$ Total number of subjects.

$\mathrm{S}=$ Standard Deviation .

$\sum \mathrm{d}^{2}=$ sum of the squared deviation.

\subsection{Inclusion and Exclusion criteria}

\section{Inclusion Criteria -}

$>$ Age between 20 to 65 years

$>$ Both patient (Male \& Female)

$>$ Musculoskeletal fracture injury

$>$ Willing patients

\section{Exclusion Criteria -}

\section{$>$ Unwilling patient \\ $>$ Hyper sensitivity patient}

\subsection{Sampling technique}

Non randomized purposive sampling technique was applied.

\subsection{Data collection tools}

A pretested, modified, interviewer administrated, semistructured questionnaire was used to collect the data.

UniversePG I www.universepg.com

\subsection{Data management and analysis}

After collection of data of the respondents were organized. Data was entered into the computer into a data base in the software package. Statistical package for the social science (SPSS) Version 16.0 (Polar engineering and consulting, Chicago) using descriptive statistics such as frequency, distribution, range, mean, and percentage. All scores and percentages was computed and presented in tabular form, charts, and graphs as appropriate. Further it was analyzed with the help of chi-square test and P-value. Finally the data was interpreted on the basis of study findings.

\subsection{Ethical consideration}

Prior to the commencement of this study, the research protocol was approved by the research committee of the academic institution. The aims and objectives of the study along with its procedure, risks and benefits were explained to the respondents in easily understandable local language and then informed consent was taken from each. Then it was assured that all information and records will be kept confidential and used only for research purpose.

\subsection{Limitation of the Study}

This preliminary study had a number of limitations. The experimental study was risk for the respondents. The sample size was comparatively small due to shortage of time and financial constraints of the research period and thus the result could not be generalized.

\section{RESULTS:}

This experimental study was conducted in Dhaka city in order to determine depression among musculoskeletal fracture in patients. A pre-tested modified interviewer administrated semi questionnaire was used to collect the information. A total of 102 patients were interviewed to collect the information. Section A contained the questions about socio-demographic characteristics; section B contained disease related variables contained treatment related variables. All the data were entered and analyzed by using statistical packages for social science (SPSS) software version 16.0 (Chicago). 
Table 1: Distribution of respondents by age $(n=102)$

\begin{tabular}{|c|c|c|}
\hline Valid & Frequency & Percent \\
\hline $20-30$ & 13 & 15.7 \\
\hline $31-40$ & 34 & 41.0 \\
\hline $41-50$ & 28 & 33.7 \\
\hline $51-60$ & 8 & 9.6 \\
\hline Total & 83 & 100 \\
\hline Missing system & 19 & \\
\hline Total & 102 & 100 \\
\hline
\end{tabular}

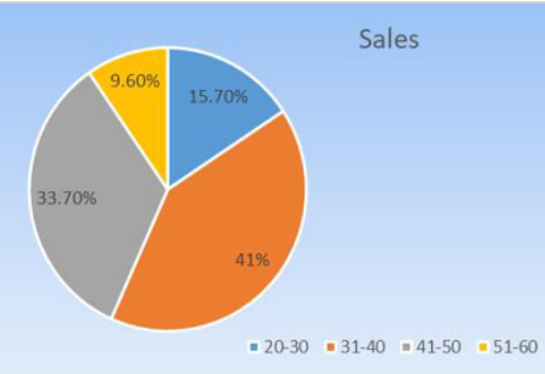

Fig 1: Distribution of respondents by age $(n=102)$.

It is found from Table 1 that the respondents belonged to age group 21-30 years $15.70 \%, 31-40$ years $41 \%$, 41 50 years $33 \%$, and $51-60$ years $9.6 \%$ depression on musculoskeletal fracture (Fig 1).

Table 2: Distribution of respondents by occupation $(\mathrm{n}=102)$

\begin{tabular}{|c|c|c|}
\hline Valid & Frequency & Percent \\
\hline Unemployed & 1 & 1.2 \\
\hline Student & 3 & 3.6 \\
\hline Day labor & 5 & 6.0 \\
\hline Housewife & 2 & 2.4 \\
\hline Rickshaw puller & 8 & 9.6 \\
\hline Service holder & 64 & 77.1 \\
\hline Total & 83 & 100 \\
\hline Missing system & 19 & \\
\hline Total & 102 & 100 \\
\hline
\end{tabular}

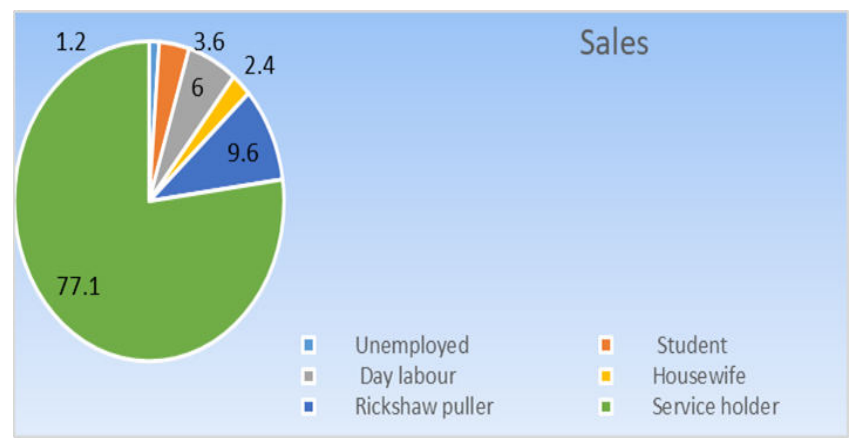

Fig 2: Distribution of respondents by occupation

$$
(n=102) \text {. }
$$

It is found from table 2 that the occupation of the respondents was unemployed $1.2 \%$, student $3.6 \%$, day labor $6.0 \%$, housewife $2.4 \%$, rickshaw puller $9.6 \%$, service holder $77.1 \%$ (Fig 2).

Table 3: Distribution of respondents by body region $(n=102)$

\begin{tabular}{|l|l|l|}
\hline Valid & Frequency & Percent \\
\hline Neck & 1 & 1.2 \\
\hline Spine & 1 & 1.2 \\
\hline Upper extremity & 44 & 53 \\
\hline Lower extremity & 37 & 44.6 \\
\hline Total & 83 & 100 \\
\hline Missing system & 19 & \\
\hline Total & 102 & 100 \\
\hline
\end{tabular}

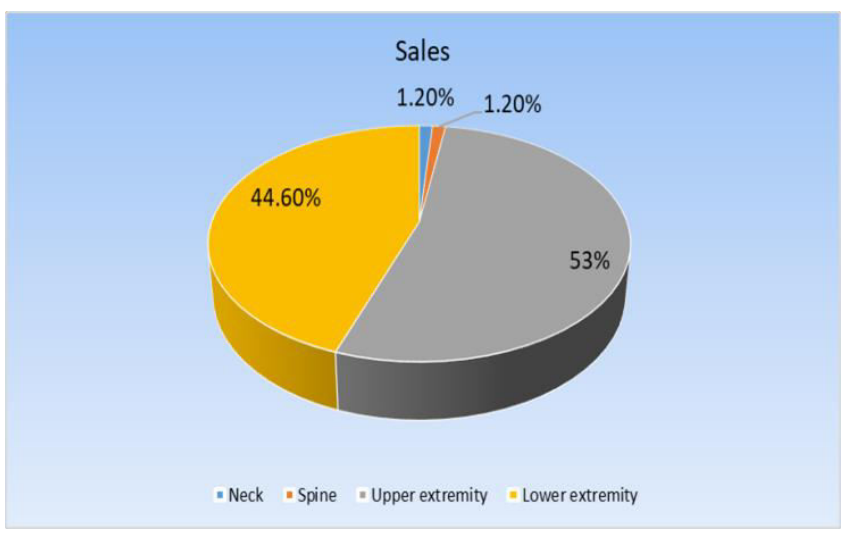

Fig 3: Distribution of respondents by body region $(n=102)$.

It is found from the Table 3 from neck $1.2 \%$, spine $1.2 \%$, upper extremity $53.0 \%$, and lower extremity $44.6 \%$ depression on musculoskeletal fracture (Fig 3).

Table 4: Distribution of respondents by severe of injury $(\mathrm{n}=102)$

\begin{tabular}{|l|l|l|}
\hline Valid & Frequency & Percent \\
\hline Moderate & 17 & 20.5 \\
\hline Serious & 2 & 2.4 \\
\hline Severe & 64 & 77.1 \\
\hline Total & 83 & 100 \\
\hline Missing system & 19 & \\
\hline Total & 102 & 100 \\
\hline
\end{tabular}

It found from the Table 4 that moderate $20 \%$, serious $2.4 \%$, severe $77.1 \%$ depression on musculoskeletal fracture (Fig 4). 


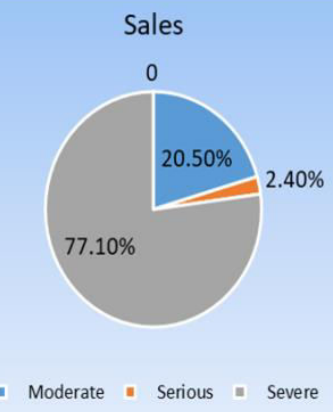

Fig 4: Distribution of respondents by severe of injury

$$
(n=102) \text {. }
$$

Table 5: Distribution of respondents by feel after injury $(\mathrm{n}=102)$

\begin{tabular}{|l|l|l|}
\hline Valid & Frequency & Percent \\
\hline I feel sad & 34 & 41.0 \\
\hline I am sad all the time & 37 & 44.6 \\
\hline I am so sad & 12 & 14.5 \\
\hline Total & 83 & 100 \\
\hline Missing system & 19 & \\
\hline Total & 102 & 100 \\
\hline
\end{tabular}

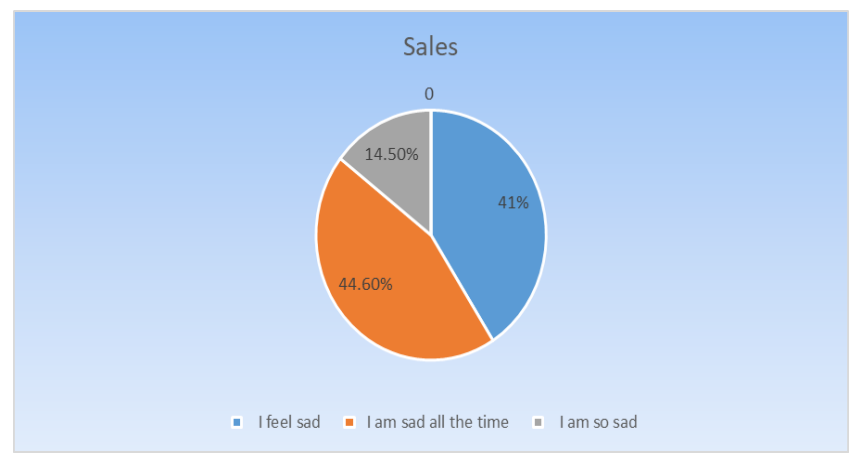

Fig 5: Distribution of respondents by feel after injury

$$
(n=102) \text {. }
$$

It found from the Table 5 that he/she feel sad $41.0 \%$, he/she is sad all the time $44.0 \%$, he/she so sad $14.5 \%$ depression on musculoskeletal fracture (Fig 5).

Table 6: Distribution of respondents by depression $(n=102)$

\begin{tabular}{|l|l|l|}
\hline Valid & Frequency & Percent \\
\hline Indicates minimal depression & 1 & 1.2 \\
\hline Indicates mild depression & 10 & 12 \\
\hline Indicates moderate depression & 68 & 81.9 \\
\hline Indicates severe depression & 4 & 4.8 \\
\hline Total & 83 & 100 \\
\hline Missing system & 19 & \\
\hline Total & 102 & 100 \\
\hline
\end{tabular}

UniversePG I www.universepg.com

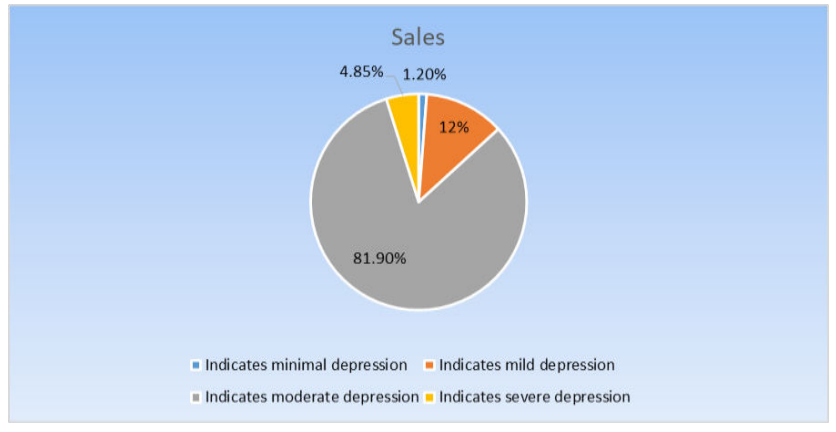

Fig 6: Distribution of respondents by depression

$$
(n=102) \text {. }
$$

I found from the table 6 that from Indicates minimal depression $1.2 \%$, Indicates mild depression $12 \%$, Indicates moderate depression $81.9 \%$, Indicates severe depression $4.8 \%$ depression on musculoskeletal fracture (Fig 6).

Table 7: Distribution of respondents by feel guilty $(n=102)$

\begin{tabular}{|l|l|l|}
\hline Valid & Frequency & Percent \\
\hline Strongly agree & 8 & 9.6 \\
\hline Agree & 75 & 90.4 \\
\hline Total & 83 & 100 \\
\hline Missing system & 19 & \\
\hline Total & 102 & 100 \\
\hline
\end{tabular}

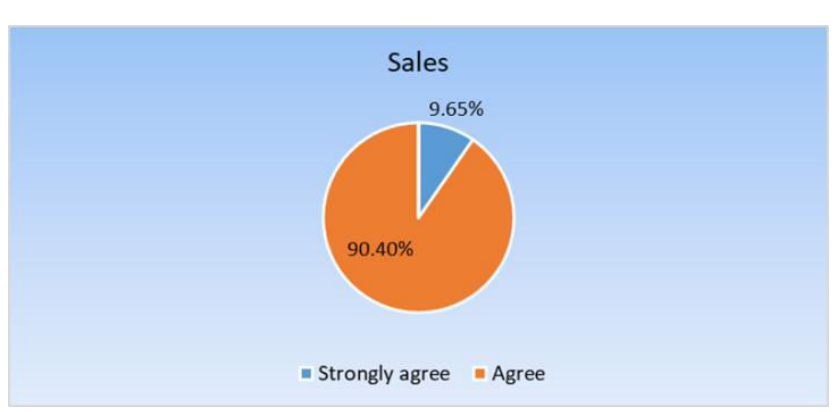

Fig 7: Distribution of respondents by feel guilty $(n=102)$.

It is found from the Table 7 reveals that he/she feel guilty strongly agree $9.6 \%$, agree $90.0 \%$ depression on musculoskeletal fracture (Fig 7).

Table 8: Distribution of respondents by depressed $\operatorname{mood}(n=102)$

\begin{tabular}{|l|l|l|}
\hline \multicolumn{1}{|c|}{ Valid } & Frequency & \multicolumn{1}{c|}{ Percent } \\
\hline Sadness & 78 & 94.0 \\
\hline Frequent weeping & 5 & 6 \\
\hline Total & 83 & 100 \\
\hline Missing system & 19 & \\
\hline Total & 102 & 100 \\
\hline
\end{tabular}




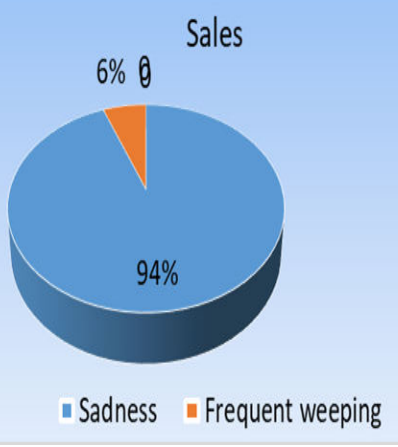

Fig 8: Distribution of respondents by depressed mood $(n=102)$.

It is found from the Table $\mathbf{8}$ reveals that the mean depressed mood of the respondent's sadness $94.0 \%$, frequent weeping $6.0 \%$ depression on musculoskeletal fracture (Fig 8).

Table 9: Distribution of respondents by agitation $(n=102)$

\begin{tabular}{|l|l|l|}
\hline Valid & Frequency & Percent \\
\hline Occasional & 6 & 7.2 \\
\hline Frequent & 77 & 92.8 \\
\hline Total & 83 & 100 \\
\hline Missing system & 19 & \\
\hline Total & 102 & 100 \\
\hline
\end{tabular}

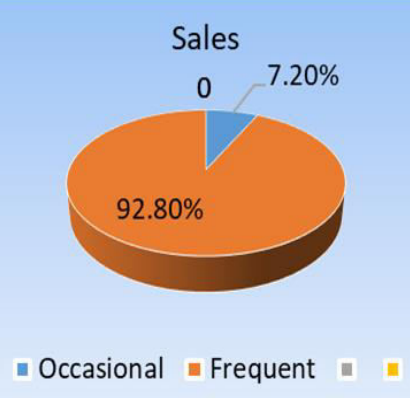

Fig 9: Distribution of respondents by agitation

$$
(n=102) \text {. }
$$

Table 10: Distribution of respondents by anxiety $(n=102)$

\begin{tabular}{|l|l|l|}
\hline Valid & Frequency & Percent \\
\hline No difficulty & 1 & 1.2 \\
\hline Tension and irritability & 74 & 89.2 \\
\hline Fear & 8 & 9.6 \\
\hline Total & 83 & 100 \\
\hline Missing system & 19 & \\
\hline Total & 102 & 100 \\
\hline
\end{tabular}

UniversePG I www.universepg.com
It is found from the Table 9 reveals that in agitation occasional $7.2 \%$, frequent $92.8 \%$ depression on musculoskeletal fracture (Fig 9).

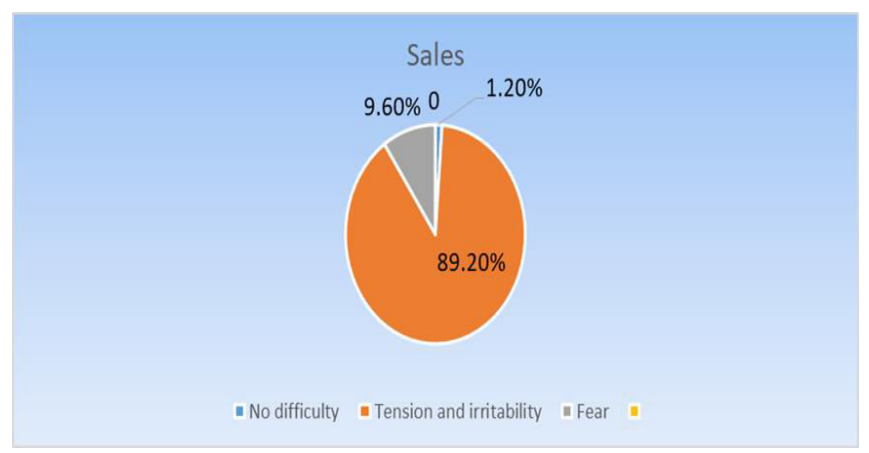

Fig 10: Distribution of respondents by anxiety $(n=102)$.

It is found from the Table $\mathbf{1 0}$ reveals that the mean anxiety no difficulty $1.2 \%$, tension irritability $89.2 \%$, fear $9.6 \%$ depression on musculoskeletal fracture (Fig 10).

Table 11: Distribution of respondents by laugh $(n=102)$

\begin{tabular}{|l|l|l|}
\hline Valid & Frequency & Percent \\
\hline As much as I always could & 83 & 100 \\
\hline Total & 83 & 100 \\
\hline Missing system & 19 & \\
\hline Total & 102 & 100 \\
\hline
\end{tabular}

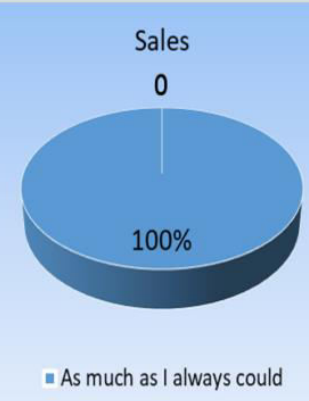

Fig 11: Distribution of respondents by laugh $(n=102)$.

It is found from the Table 11 reveals that the mean laugh of the respondents he/she as much always could laugh $100 \%$ on musculoskeletal fracture (Fig 11).

\section{DISCUSSION:}

It is found that the respondents belonged to age group 21-30years $15.70 \%$, 31-40years $41 \%$, 41-50 years $33 \%, 51-60$ years $9.6 \%$ depression on musculoskeletal 
fracture, the occupation of the respondents were unemployed $1.2 \%$, student $3.6 \%$, day labor $6.0 \%$, housewife $2.4 \%$, rickshaw puller $9.6 \%$, service holder $77.1 \%$ and neck $1.2 \%$, spine $1.2 \%$, upper extremity $53.0 \%$, and lower extremity $44.6 \%$ depression on musculoskeletal fracture the mean depressed mood of the respondent's sadness $94.0 \%$, frequent weeping $6.0 \%$ depression on musculoskeletal fracture. The prevalence of depression in our sample was high, with $45 \%$ of our cohort screening positively for moderate, moderate-to-severe, or severe depression and $16.7 \%$ screening positively for moderate-to-severe or severe depression. These levels are extremely high relative to those in the population at large. The prevalence of depression in the general population ranges from $3.2 \%$.

These high levels of depression are consistent with findings in other studies documenting the prevalence of psychological distress following physical trauma (Wilhelm et al., 2003). The incidence of psychological distress has ranged between $23 \%$ and $41 \%$ in a variety of studies with widely divergent populations and outcome instruments. In the Lower Extremity Assessment Project (LEAP) population (patients with severe lower-extremity injuries) the incidence of moderateto-severe depression was $41.8 \%$ and the incidence of severe depression was $15.3 \%$. Most depressionscreening instruments involve questions that are directly related to physical status and vitality. Trauma patients, who have difficulty with activities of daily living, chronic pain, or continuing narcotic requirements, may confound depression scores by scoring poorly on items related to vitality, energy, or sleep disturbance. Secondarily, there have been criticisms that the BDI overestimates the severity of depressive symptoms in patients with somatic symptoms (Kessler et al., 2003).

The level of perceived depression and disability might also have been influenced by the patient's socioeconomic status, medical comorbidity, and health habits; however, such data were not collected. It has been shown that adequate financial and familial support can minimize the impact of injury on perceived physical and emotional disability. The review of the literature offers unsystematised but extensive empirical support for the concept of acomplex post-traumatic syndrome in survivors of prolonged, repeated victimization. This previously undefined syndrome may coexist with simple PTSD, but extends beyond it. The syndrome is characterized by a pleomorphic symptom picture, enduring personality changes, and high risk for repeated harm, either self-inflicted or at the hands of others. Psychological acceptance (acceptance) and emotional intelligence (EI) are two relatively new individual characteristics that are hypothesised to affect wellbeing and performance at work. This study compares both of them, in terms of their ability to predict various well-being outcomes (i.e. general mental health, physical well-being, and job satisfaction). In making this comparison, the effects of job control are accounted for; this is a work organisation variable that is consistently associated with occupational health and performance.

Acceptance predicted general mental health and physical well-being but not job satisfaction, and job control was associated with job satisfaction only. Discussion focuses on the theoretical and applied implications of these findings. These include support for the suggestion that not controlling one's thoughts and feelings (as advocated by acceptance) may have greater benefits for mental well-being than attempting consciously to regulate them. To our knowledge, this study is the first to explore the relative abilities of acceptance and EI to predict well-being outcomes (general mental health, physical well-being and job satisfaction). These individual difference constructs are both fairly new to the field of occupational health psychology and may prove of equal, if not greater, importance than longer established constructs, such as A behaviour pattern, locus of control and negative affectivity.

The study was conducted National Institute of Traumatology and Orthopedic Rehabilitation (NITOR), Dhaka. Psychological therapy is very important in musculoskeletal fracture patient for mental support.102 participate in this study.It is found that the occupation of the respondents were unemployed $1.2 \%$, student $3.6 \%$, day labor $6.0 \%$, housewife $2.4 \%$, rickshaw puller $9.6 \%$, service holder $77.1 \%$. 
It is found from the from neck $1.2 \%$, spine $1.2 \%$, upper extremity $53.0 \%$, and lower extremity $44.6 \%$ depression on musculoskeletal fracture. Indicates minimal depression $1.2 \%$, indicates mild depression $12 \%$, indicates moderate depression $81.9 \%$, indicates severe depression $4.8 \%$ depression on musculoskeletal fracture. It found that he/she feel sad $41.0 \%$, he/she is sad all the time $44.0 \%$, he/she so sad $14.5 \%$ depression on musculoskeletal fracture. Anxiety no difficulty $1.2 \%$, tension irritability $89.2 \%$, fear $9.6 \%$ depression on musculoskeletal fracture. Study concludes that the prevalence of clinically relevant depression approached $45 \%$ in a diverse cohort of orthopedic trauma patients. Global disability is strongly correlated with depression. The presence of an open and close fracture may also increase the risk of depression.

\section{CONCLUSION AND RECOMMENDATIONS:}

Study concludes that the prevalence of clinically relevant depression approached $45 \%$ in a diverse cohort of orthopedic trauma patients. Global disability is strongly correlated with depression. The presence of an open and close fracture may also increase the risk of depression. Based on the study findings, the following recommendations are depression among musculoskeletal fracture patients in a tertiary referral hospital in Bangladesh.

1. This study is a short term study, it is therefore necessary to do a long term study to make the result more valid.

2. Sample studied was small so larger population is recommended.

3. No standard protocol of assessment was used for this study.

4. In future other psychotherapy technique should be considered.

5. Long term of psychotherapy and trauma center modification has to be analyzed in future.

6. In future needed a large sample.

\section{ACKNOWLEDGEMENT:}

Firstly, I am grateful to Almighty God to give me the ability to complete this project. I give thanks to my respected Head of the Department, Dr. Nasima Yasmin, Assistant Professor, BPT, MPT (Ortho.), MPH for his inspiration and support. Also I would like UniversePG I www.universepg.com to thank my parents and my BPT-26 ${ }^{\text {th }}$ batch \& specially Sharmin Sultana for supporting me spiritually throughout writing this study.

\section{CONFLICTS OF INTEREST:}

The author's declared there are no conflicts of interest to publish the present work.

\section{REFERENCES:}

1) Amit Chaitanya, Pawan Kumar, (2015). Psychological distress fowling orthopaedic trauma - A Review, Advanced Medical and Dental Sciences Research, 31: 4.

2) Blazer DG, Kessler RC, McGonagle KA, Swartz MS (1994). The prevalence and distribution of major depression in a national community sample: the National Comorbidity Survey. Am J Psychiatry; 151: 979-86. https://pubmed.ncbi.nlm.nih.gov/8010383/

3) Briere J. and Runtz M. (1987). Post Sexual Abuse Trauma: Data and Implications for Clinical Practice, J. of Interpersonal Violence, 2(4): 367-379. https://doi.org/10.1177/088626058700200403

4) Butcher JL, MacKenzie EJ, Cushing B. et al (1996). Long-term outcomes after lower extremity trauma. J Trauma; 41(1): 4-9. https://doi.org/10.1097/00005373-199607000$\underline{00002}$

5) Demyttenaere K, and De Fruyt J. (2003). Getting what you ask for: on the selectivity of depression rating scales. Psychotherapy Psychosomatic. 72: 61-70.

6) Fernald LD, (2008). Psychology: Six perspectives (pp. 12-15). Thousand Oaks, CA: Sage Publications.

https://www.amazon.com/Psychology-Perspectives-L-Dodge-Fernald/dp/1412938678

7) Frank W. Bond \& Emma J. Donaldso-feilder, (2010). The relative importance of psychological acceptance and emotional intelligence to workplace well-being, British Journal of Guidance \& Counselling, 187-203. https://doi.org/10.1080/08069880410001692210

8) Glancy KE, Glancy CJ, Lucke JF, (1992). A study of recovery in trauma patients. $J$ Trauma; 33: 602-9. 
9) Hamilton M. (1960). Hamilton Depression Rating Scale. J Neurol Neurosurgeon Psychiatry, 23, Pp. 56-62.

https://dcf.psychiatry.ufl.edu/files/2011/05/HA MILTON-DEPRESSION.pdf

10) Hilberman E. (1980). Overview The wife beater wife reconsidered, American journal of psychiatry, 137, 1336-1343.

https://ajp.psychiatryonline.org/doi/abs/10.1176/ ajp.137.11.1336

11) IASP, (2017). Pain (online) https://www.iasppain.org/Education/Content.asp $\mathrm{x}$ ? ItemNumber $=1698 \#$ Pain.

12) Katherine, Abel (2013). Official CPC Certification Study Guide. American Medical Association. Pp. 108.

13) Kessler RC, Berglund P, Demler O, Jin R, Koretz D, Merikangas KR, Rush AJ, Walters EE, and Wang PS. (2003). National Comorbidity Survey Replication. The epidemiology of major depressive disorder: results from the National Comorbidity Survey Replication (NCS-R). JAMA. 289: 3095-105.

14) Lasa L, Ayuso-Mateos JL, Vazquez-Barquero JL, Diez-Manrique FJ, Dowrick CF. (2000). The use of the Beck Depression Inventory to screen for depression in the general population: a preliminary analysis. J Affect Disorder; 57: 261-5.

15) McCarthy ML, MacKenzie EJ, Edwin D, (2003). Psychological distress associated with severe lower-limb injury. 85: 1689-97.

16) Nahid SAA, Alam MS, Shakib KM, and Roy RC. (2019). Assessment, monitoring, and awareness of garment workers regarding the prevalence of tuberculosis in Savar, Dhaka, Eur. J. Med. Health Sci., 1(5), 30-40. https://doi.org/10.34104/ejmhs.0193040

17) Parker G, Hilton T, Bains J, Hadzi-Pavlovic D. (2002). Cognitive-based measures screen- ing for depression in the medically ill: the DMI-10 and the DMI-18. Acts Psychiatry Scand.; 105: 419-26.

18) Patricia L. Andres, MS, PT, Suzanne M. Morrison et al, (2016). State of Wisconsin Group Health Insurance Program Community Network.

19) Patten SB, Sedmak B, Russell ML. (2001). Major depression: prevalence, treatment utilization and age in Canada. Can J Clin Pharmacology; 8:133-8.

20) Rannaparekh, (2017). Trauma American psychiatry association https://www.psychiatry.org/patients-families/ depression/what-is-depression

21) Roy RC, Sahabuddin M, Jubayer M, Uddin J, and Saha B. (2019). Nutritional status of the adolescent boys of a recognized charitable orphanage in Dhaka city, Bangladesh. Eur. J. Med. Health Sci., 1(3), 10-18. https://doi.org/10.34104/ejmhs.01018

22) Wikipedia (2018). Abbreviated injury scale (online) https://en.wikipedia.org/wiki/Abbreviated_Injur y_Scale

23) Wikipedia (2018). Distress (online) https://en.wikipedia.org/wiki/Mental_distress

24) Wikipedia (2018) Emotion (online) https://en.wikipedia.org/wiki/Emotion.

25) Wikipedia (2018). Psychology (online) https://en.wikipedia.org/wiki/Psychology.

26) Wikipedia (2018). Disability (online) https://en.wikipedia.org/wiki/Disability

27) Wilhelm K, Mitchell P, Slade T, Brownhill S, Andrews G. (2003). Prevalence and correlates of DSM-IV major depression in an Australian national survey. J Affect Disorder; 75: 155-62. https://doi.org/10.1016/s0165-0327(02)00040-x

Citation: Roy K, Hossain S, Lilon MAA, Yasmin N, Sarkar S, Roy K, Haque A, Jobayer M, Saha B, and Roy RC. (2020). Assessment of depression among musculoskeletal fracture patients in a tertiary referral hospital in Bangladesh, Eur. J. Med. Health Sci., 2(6), 134-144. https://doi.org/10.34104/ejmhs.020.01340144 () 